\title{
MENIPEIA, DESTRONAMENTO E O BOBO EM UTOPIA, DE THOMAS MORE
}

\section{MENIPPEA, DETHRONEMENT AND THE FOOL IN UTOPIA, BY THOMAS MORE}

Diego Gomes do Valle*

Resumo: O objetivo deste artigo é discorrer sobre alguns conceitos do pensador Mikhail Bakhtin com vistas a suas possíveis aplicações na obra Utopia, de Thomas More. Os três conceitos que dão título ao presente artigo estarão na base de nosso estudo, de maneira que nossa pretensão se resume a esclarecê-los e a iluminar a obra de More.

Palavras-chave: Menipeia. Mikhail Bakhtin. Thomas More.

Abstract: The purpose of this paper is to discuss some concepts of the philosopher Mikhail Bakhtin in view of their possible applications in Thomas More's Utopia. The three concepts that named this article will form the basis of our study, so that our pretension is to clarify them to illuminate the More's work.

Keywords: Menippea. Mikhail Bakhtin. Thomas More.

INTRODUÇÃO

"La imagen utópica es un cuadro de lo que 'debe ser', lo que el autor de ella desearía que fuese real"

(Martin Buber) ${ }^{1}$

Difícil tarefa é a de um sujeito que decide compreender outro sujeito ou outra

*Doutorando em Teoria e História Literária (UNICAMP). E-mail: dydydyego@hotmail.com

${ }^{1}$ BUBER, Martin. Caminos de Utopía, p.17. obra com quase 500 anos de afastamento. Tarefas semelhantes ocuparam alguns personagens borgianos. Por exemplo, Averroes $^{2}$, tradutor e comentador dos textos aristotélicos, na ânsia de traduzir "tragédia" e "comédia”, sem possuir a ideia de teatralidade, que antecede a subdivisão do gênero drama, traduziu toscamente tais conceitos. O narrador do conto finaliza sua

\footnotetext{
${ }^{2}$ La busca de Averroes, do livro de contos El Aleph (2004), de Jorge Luis Borges.
} 
narração dizendo: "En la historia anterior yo quise narrar el proceso de una derrota" (BORGES, 2004, p.116).

Também o inesquecível Pierre Menard ${ }^{3}$ comprovou que, mesmo tentando ser um novo Cervantes, e reescrevendo exatamente o mesmo texto do criador de Sancho (tenho certeza de que o leitor conferiu cada palavra, cada vírgula daquele trecho), são dois textos diferentes; Pierre Menard não é Cervantes, porque não são, porque são o que são.

Saindo do labirinto de Borges, iniciamos nosso artigo sabedores de nossos possíveis equívocos e/ou limitações impostas pelo tempo e pela relação que se nos impõe. Porém, tal como Averroes, iremos chegar ao limite do que podemos colaborar com nossa compreensão, e articular, com o risco de cairmos no anacronismo, as teorias do russo Mikhail Bakhtin com alguns pontos específicos da obra Utopia, de Thomas More.

Pela riqueza de referências inseridas na obra renascentista, que se perdem diante de nossos olhos, temos de ser cuidadosos para aceitar esta cegueira momentânea e tatear com muita atenção qualquer trecho que evocarmos para comprovar alguma observação nossa.

Começaremos expondo a visão que Bakhtin formulou sobre o Renascimento no seu livro A cultura popular na Idade Média e no Renascimento: o contexto de François Rabelais (1999). Dessa forma, o risco de má compreensão sobre essa época tão profícua para humanidade se reduz

\footnotetext{
${ }^{3}$ No conto Pierre Menard, autor del Quijote, do livro de contos Ficciones (2001), no qual Borges ilustra o desejo de ser o outro, e não apenas tateá-lo e assumir resignadamente a impossível fusão.
}

substancialmente, uma vez que endossamos (juntamente com uma plêiade considerável de estudiosos) a leitura de Bakhtin sobre tal período da história.

Passaremos a analisar a noção de Sátira Menipeia e sua influência - que, de acordo com Bakhtin, é sentida na literatura universal-, na obra de More. Posteriormente, refletiremos sobre alguns conceitos que são unidos umbilicalmente e que nos serão úteis para a hipótese deste artigo: o destronamento e a carnavalização. Por fim, discutiremos a função desempenhada pelo Bobo na obra de More, bem como a definição que Bakhtin dá para este personagem.

É sabido que a contemplação do todo generaliza as partes, e as partes decompostas causam a incompreensão do todo. Ou seja, esta parte da Utopia que analisaremos não é a Utopia, mas é também. Para compreender esta parte da obra, deixaremos de contemplar o restante dela, tal como quando contemplamos um quadro. Deve-se não contemplar uma série de coisas para que haja a contemplação do quadro, é a limitação do observador que possibilita a própria compreensão. Se não houvesse a limitação, retomando Borges, seria o Aleph.

\section{HUMANISMO RENASCENTISTA, SEGUNDO MIKHAIL BAKHTIN \\ "O Renascimento é a culminância da vida carnavalesca"}

(Mikhail Bakhtin)4

Antes de entrar no período que nos interessa para os fins deste trabalho, é bom

${ }^{4}$ BAKHTIN, Mikhail. Problemas da poética de Dostoiévski, p.130. 
que se digam algumas palavras sobre as pretensões de Bakhtin ao historicizar as tendências cômicas, satíricas, paródicas, grotescas, enfim, o lado não-oficial da cultura. O filósofo russo encontra no romance o gênero ideal para, em potência, ilustrar a sua (de Bakhtin) visão de mundo: uma visão livre, humana, sem hierarquias, aberta ao outro. Salientamos o "em potência", pois nem sempre tal filosofia se realiza no romance, mas o fato é que, para Bakhtin, os outros gêneros (épico, lírico, dramático), por uma série de motivos específicos, não têm o potencial do romance, enquanto antigênero, para realizar todas as possibilidades humanas.

Neste panorama, é necessário demonstrar historicamente as fontes das quais o romance bebeu para se configurar como o gênero mais aberto, incompleto da literatura. Na Antiguidade, Bakhtin encontra no Romance Grego ${ }^{5}$, nos Diálogos, na Sátira Menipeia, um passo significativo na desconstrução do herói épico, idealizado por excelência. Já no Renascimento, o russo encontra em Rabelais (1494-1553) a manifestação suprema do homem em sua grotesca humanidade. É no livro A Cultura Popular na Idade Média e no Renascimento: o contexto de François Rabelais (1999) que Mikhail explora o contexto possível para Rabelais representar seus personagens que usufruem de sua humanidade ao máximo.

Para Bakhtin, é interessante localizar esta representação humana, demasiadamente humana, pois segundo ele, esta é

\footnotetext{
"É necessário compreender a terminação "romance" na perspectiva bakhtiniana, que vê os gêneros dentro da "grande história", na sua evolução constante.
}

uma das características principais do gênero romance. Interessa mostrar "nem o ser biológico isolado nem o egoísta indivíduo burguês, mas o povo, um povo que na sua evolução cresce e se renova constantemente" (BAKHTIN, 1999, p.17). Ou seja, no período histórico em questão, houve uma nova representação artística do homem, a qual visava um despojamento dos elementos externos (a ideologia religiosa especialmente) para uma plena configuração do homem em sua relação consigo mesmo, com o mundo e com o outro:

A forma do grotesco carnavalesco cumpre funções semelhantes; ilumina a ousadia da invenção, permite associar elementos heterogêneos, aproximar o que está distante, ajuda a liberar-se do ponto de vista dominante sobre o mundo, de todas as convenções e de elementos banais e habituais, comumente admitidos; permite olhar o universo com novos olhos, compreender até que ponto é relativo tudo o que existe, e portanto permite compreender a possibilidade de uma ordem totalmente diferente do mundo (BAKHTIN, 1999, p.30).

Bakhtin, desta forma, encontra no Renascimento o ápice deste "novo olhar" a todas as hierarquias sociais. Tudo que é "alto" é rebaixado de alguma forma, para demonstrar o quão falível e caótico é o mundo. Uma vez que as hierarquias são implodidas, o homem pode exercer a sua liberdade de forma plena, pois já não há amarras impostas por poder algum.

Dessa forma, não interessa para Bakhtin estudar a simbologia de Michelângelo, a astronomia de Copérnico 
ou Galileu, a filosofia de Telésio ou os estudos mnemônicos de Bruno; ele quer refletir sobre o riso de Rabelais e a insanidade de Erasmo.

Toda a ilustração de Bakhtin, no livro citado, se dá na intenção de corroborar este descontentamento com o mundo burguês que se impunha, ao mesmo tempo em que o homem se descobria em sua potencialidade quase divina. Algo que na Idade Média era impossível de se imaginar.

Já que falamos de impossibilidade, passemos para o próximo tópico que trata de assunto semelhante.

\section{SÁTIRA MENIPEIA: O POSSÍVEL NO IMPOSSÍVEL}

"Escatología significa consumación de la creación; utopía, desenvolvimiento de las posibilidades que encierra la convivencia humana en un orden justo"

\section{(Martin Buber) $^{6}$}

O gênero em questão surge por volta de II a.C com o pensador Menipo de Gádara, desenvolve-se desde então e passa até por algumas narrativas bíblicas, de acordo com Bakhtin. Varro, Apuleio, Sêneca e, em especial, Luciano, de quem More foi tradutor e estudioso, foram grandes representantes deste gênero. Deixamos claro de antemão que não afirmamos a influência deste gênero na Utopia, em especial, pois demandaria um esforço significativo a sustentação de tal hipótese. O que deixaremos claro é a semelhança de propostas, de intencionalidade autoral,

\footnotetext{
${ }^{6}$ Caminos de Utopía, p.18.
}

de criação artística literária que há entre a Menipeia e o gênero utópico.

Deixemos que Bakhtin caracterize a Menipeia?:

A menipeia liberta-se totalmente daquelas limitações histórico-memoralísticas que ainda eram inerentes ao diálogo "socrático" (embora a forma memorialística externa às vezes se mantenha), está livre das lendas e não está presa a quaisquer exigências da verossimilhança externa vital. A menipeia se caracteriza por uma excepcional liberdade de invenção do enredo e filosófica. Isto não cria o menor obstáculo ao fato de os heróis da menipéia serem figuras históricas e lendárias (Diógenes, Menipo e outros). É possível que em toda a literatura universal não encontremos um gênero mais livre pela invenção e a fantasia do que a menipeia (1997, p.114).

Esta primeira descrição trata do primeiro traço, que é o desenraizamento com o real, com a lógica do real. Para nossos dias, parece algo tautológico, mas de maneira alguma o era na época citada. Também fica clara a diferença entre o diálogo socrático e a menipeia. Se lembrarmos da República, de Platão, e compararmos com a Utopia, de Thomas More, perceberemos que no texto

\footnotetext{
${ }^{7}$ Utilizaremos as definições contidas no livro Problemas da Poética de Dostoiévski (1999), onde Bakhtin utiliza seus estudos clássicos, acrescentados nesta segunda versão do livro, para localizar Dostoiévski na linhagem de escritores influenciados pela sátira menipeia. No Brasil, temos como representante maior Machado de Assis, que foi muito influenciado por Luciano. Uma passagem ilustrativa desta herança luciânica é o capítulo "O Delírio", do romance Memórias Póstumas de Brás Cubas, o qual descreve a viagem do narrador sobre um hipopótamo.
} 
platônico não há nenhuma situação extraordinária para proporcionar o discurso de Sócrates, temos, sim, um tratado político-filosófico por meio do método maiêutico. Abaixo, veremos a contraposição do gênero utópico.

Seguindo na definição, Bakhtin deixa ainda mais evidente a hipótese que propomos, a saber, de aproximar as intenções do gênero utópico com a menipeia:

A particularidade mais importante do gênero da menipeia consiste em que a fantasia mais audaciosa e descomedida e a aventura são interiormente motivadas, justificadas e focalizadas aqui pelo fim puramente filosófico-ideológico, qual seja, o de criar situações extraordinárias para provocar e experimentar uma ideia filosófica: uma palavra, uma verdade materializada na imagem do sábio que procura essa verdade. Cabe salientar que, aqui, a fantasia não serve à materialização positiva da verdade mas à busca, à provocação e principalmente à experimentação dessa verdade. Com este fim, os heróis da menipeia sobem aos céus, descem ao inferno, erram por desconhecidos países fantásticos, são colocados em situações extraordinárias reais (grifos nossos) (1997, p.114).

Se pensarmos no enredo básico do gênero utópico, teremos um sujeito que viajou, conheceu um povo/lugar, sobre o qual ninguém havia tido notícias, retornou ao seu país e está contando a alguém tudo que apreendeu sobre aquele lugar e sobre o costume de tal povo. Este povo sempre é tido como excepcionalmente avançado em questões sociais, culturais, tecnológicas, políticas, religiosas etc. A possibilidade que um pensador com grande competência filosófica tem de experimentar uma verdade, uma ideia de mundo ideal, realiza-se no gênero utópico, pois o fato de ser uma terra distante, sem compromissos com o real, faz com que a liberdade criativa seja total. Também o fato de o narrador ser o único a testemunhar, ser o propagador do testemunho, facilita a estrutura da história.

Sendo assim, se a motivação de uma Menipeia é experimentar uma verdade, sem compromissos com os protocolos do real, no gênero utópico, temos o mesmo, é bem verdade, sem os elementos satíricos, paródicos (mais enfáticos na Menipeia). Uma vez mais ponderamos: não se trata de correspondência, mas de analogias entre gêneros e épocas.

Algo muito comum nas Menipeias, e, como vimos, na visão humanista do Renascimento, é o destronamento de convenções estabelecidas autoritariamente. No tópico seguinte, veremos como este destronamento se dá, na Utopia, na relação dos sujeitos com o valor atribuído ao capital.

\section{DESTRONAMENTO: O CAPITAL EM UTOPIA}

"Para la escatología - aunque en su forma elemental, profética, prometa al hombre una participación activa en la llegada de la redención - el acto decisivo viene de arriba; para la utopía, todo está sometido a la voluntad consciente del hombre, y hasta puede 
calificársela de imagen de la sociedad esbozada como si no hubiera otros factores que esa voluntad"

(Martin Buber) $^{8}$

Trataremos agora de um elemento fundamental da composição social da Utopia, o tratamento do capital entre os utopianos. Antes da definição, lembramos que em outra famosa utopia - a Cidade do Sol, de Campanella ${ }^{9}$-, reina uma concepção do dinheiro muito similar, especialmente no que concerne ao valor atribuído à moeda em detrimento dos demais valores humanos.

Trata-se de rebaixar, destronar o capital, retirar toda a "aura" existente no dinheiro, para retornar a um estado de coisas no qual a comunidade - e não a sociedade possuía valores superiores aos que se instalaram após as comercializações e ao acúmulo de capital como valor supremo de vida. No caso de More, temos um filósofo muito sensível às vicissitudes de seu tempo, bem como preocupado com os desdobramentos da cultura do acúmulo e da 'divinização' do capital. Este problema é percebido e explicitado na Utopia nos seguintes termos:

Nenhuma criatura viva é voraz e gananciosa por natureza, mas apenas pelo medo de sofrer privações; e, no caso do ser humano, a razão é a simples vaidade, a ideia de que se é melhor do que os outros quando se

\footnotetext{
${ }^{8}$ Caminos de Utopía, p.18.

9 "Os habitantes não recebem dinheiro, mas trocam com as mercadorias de que precisam, sendo que, muitas vezes, também as compram com moedas. Mas, de todo o coração, riem-se os meninos solares ao verem tanta abundância de coisas deixadas por tão poucas bagatelas" (CAMPANELLA, 1978, p.262).
}

podem ostentar grandes propriedades e todo tipo de luxo supérfluo. Esse tipo de coisa, porém, não acontece no esquema que vigora em Utopia (MORE, 2009, p.105).

More, na primeira parte da Utopia, explicita bem o retrato da Inglaterra daquele momento e sua respectiva crítica. Sobre esta relação de via dupla, bem aponta Benedito Nunes (1969), num ensaio chamado "Das utopias", que, segundo ele, se dividem num olhar de Jano:

Bifrontais, as utopias proscrevem as instituições e os costumes de uma época, prescrevendo leis e modos de vida diferentes para uma sociedade sem época. O lado crítico e o lado prospectivo são as duas faces alternantes das criações utópicas. No esforço de corrigir, emendar e ultrapassar a realidade que refletem e contra a qual se voltam, essas criações oscilam entre a compreensão reflexiva das possibilidades humanas ainda em suspenso e a negação imaginária do real de que se desprendem (NUNES, 1969, p.31).

Como mostra do que vimos argumentando, encontramos na Utopia a seguinte passagem exemplificando o que dissemos no início deste item:

Refiro-me, em especial, ao fato de não usarem dinheiro, mas de apenas o conservarem para uma eventual emergência. Enquanto nenhuma preocupação vem comprometer-lhes a tranquilidade, a prata e o ouro, que são a matéria-prima do dinheiro, são conservados de modo que ninguém lhes tribute mais respeito do que 
aquele a que fazem jus por seu valor intrínseco (MORE, 2009, p.114).

Este é um exemplo do que chamamos de destronamento. Para compreender este conceito, é necessário que se compreenda que ele se insere na visão de mundo do Carnaval, tal como Bakhtin o define:

O carnaval é um espetáculo sem ribalta e sem divisão entre atores e espectadores. No carnaval todos são participantes ativos, todos participam da ação carnavalesca [...] Esta é uma vida desviada da sua ordem habitual, em certo sentido uma vida "às avessas", um "mundo invertido" ("monde à l'envers") (BAKHTIN, 1997, p.122).

Nesta ação carnavalesca, a coroação-destronamento é de especial relevância:

é um ritual ambivalente biunívoco, que expressa a inevitabilidade e, simultaneamente, a criatividade da mudança-renovação, a alegre relatividade de qualquer regime ou ordem social, de qualquer poder e qualquer posição (hierárquica) (BAKHTIN, 1997, p.124).

Ou seja, trata-se de ridicularizar aquilo que possui um status acima das demais relações humanas. Que é que fazem More e Campanella com o capital e seu acúmulo? Ridicularizam e mostram como tal adoração pecuniária é vã, contrária à ordem humana ideal. Eis uma mostra da visão de mundo utopiana:

Outra coisa que os enche de surpresa é verificar que um material tão inútil quanto o ouro possa ser considerado, no mundo inteiro, muito mais importante do que os seres humanos, ainda que esse altíssimo valor lhe tenha sido atribuído por eles próprios (MORE, 2009, p.120).

Sendo assim, a atitude reinante entre os utopianos é de desprezo pelo acúmulo de bens e pela adoração de algo que nos afasta das verdadeiras relações interpessoais, como vemos neste trecho: "A Natureza, porém, não deu ao ouro e à prata nenhuma função que não seja perfeitamente dispensável; foi a loucura humana que os fez preciosos por serem raros" (MORE, 2009, p.115). Ao se abrir mão das relações pecuniárias, as relações humanas (no sentido renascentista mesmo) surgem como a única possível, a verdadeira.

O desprezo (destronante) pelo ouro, e mais genericamente pela valoração do capital, fica evidente nos usos destinados aos metais preciosos e às joias:

Tanto nas residências particulares quanto nos refeitórios comunitários, utilizam a prata e o outro para a fabricação dos mais simples utensílios domésticos, como por exemplo, os urinóis. Também usam correntes e grilhões de ouro para prender os escravos, e todos os que praticam crimes realmente graves são forçados a usar anéis de ouro nas orelhas e nos dedos, um colar de ouro no pescoço e até uma tiara de ouro na cabeça. Na verdade, fazem o possível para tornar esses metais desprezíveis (MORE, 2009, p.116).

Mais adiante, ficamos sabendo que as joias se convertem em brinquedos para crianças, e que elas são mais tarde 
desprezadas pelos pequenos. Inclusive, uma anedota que ilustra toda ligação destronante que estabelecemos é a história dos embaixadores anemolianos. Estes senhores representam exatamente o choque cultural que teríamos se nós (não só os contemporâneos de More) conhecêssemos a Utopia: a inversão de valores concernentes ao capital. Ao ver tais embaixadores, as crianças utopianas não entendem aqueles senhores vestidos e ornamentados com aquilo que existe de mais desprezível a elas. A isso, uma mãe responde ao filho: "Cala-te, filho, deve ser algum bobo que veio junto com a comitiva" (MORE, 2009, p.119).

Bakhtin nos lembra, sempre, que o destronamento, a atitude carnavalizante, busca sempre encontrar a Verdade escondida por trás de pretensas verdades. More detecta que a verdade financeira, estritamente, leva à corrupção dos seres, ao seu progressivo individualismo (avesso à visão de mundo popular do carnaval renascentista).

Se no enredo da Utopia houve este destronamento, em sua primeira parte há um personagem tipicamente carnavalizante: 0 bobo; é sobre ele que trataremos agora.

\section{A VERDADE DESNUDADA: O BOBO}

"En la revelación, la visión de lo justo se consuma en la imagen de un tiempo perfecto: como escatología mesiánica; en la idea, la visión de lo justo se consuma en la imagen de un espacio perfecto: como utopía"

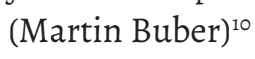

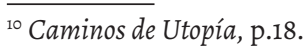

O personagem Bobo, que teria seu apogeu no Renascimento, era conhecido desde a mais recuada Antiguidade e ressurge na Idade Média nos âmbitos folclóricos e de inclinações satírica e paródica, ou seja, âmbitos populares, não-oficiais. Nas peças de Shakespeare, por exemplo, não raro este personagem aparece como a "verdade dita risonhamente". A título de exemplo, numa tragédia das mais cruéis como Rei Lear, lá está o Bobo ao lado do Rei, sendo impiedoso ao dizer a triste e trágica realidade ${ }^{11}$.

Bakhtin, no livro sobre Rabelais, diz da legitimidade que o riso possuía já na Idade Média:

O riso acompanhava também as cerimônias e os ritos civis da vida cotidiana: assim, os bufóes e os 'bobos' assistiam sempre às funções do cerimonial sério, parodiando seus atos (proclamação dos nomes dos vencedores dos torneios, cerimônias de entrega do direito de vassalagem, iniciação dos novos cavaleiros, etc.) (BAKHTIN, 1999, p.4).

Na obra de Thomas More que analisamos, sua presença é mínima, só aparece no Livro I. No entanto, sua "verdade" ecoa forte, devido aos ataques de denúncia que se comprovavam no mundo real. Adiante veremos o trecho e sua respectiva análise. Por ora, fiquemos com as definições de Bakhtin para este personagem ${ }^{12}$. Num artigo chamado "Funções do Trapaceiro, do Bufão e do Bobo no romance",

\footnotetext{
"Consta que na casa de Thomas More havia um bobo chamado Henry Patenson. (Cf. nota explicativa $n^{\circ} 96 \mathrm{da}$ edição da Utopia da Martins Fontes, utilizada por nós neste artigo).

${ }^{12}$ Traremos as definições de Bakhtin contidas no livro Questões de Literatura e Estética: a teoria do romance (1998).
} 
Bakhtin discorre sobre estes personagens desnudantes das pretensas verdades: "O trapaceiro, o bufão e o bobo criam em volta de si microcosmos e cronotopo especiais" (BAKHTIN, 1998, p.275). Ou seja, quando eles surgem, há um deslocamento proposital para um mundo à parte, uma relação com a realidade que é diferente. Percebemos isso na tolerância dos personagens sérios para com o Bobo, o tom invectivo das ofensas é aturado e ouvido integralmente, sempre: "Uma particularidade e um direito são características delas: são estrangeiras nesse mundo, elas não se solidarizam com nenhuma situação de vida existente nele, elas veem o avesso e o falso de cada situação" (BAKHTIN, 1998, p.276). Vejamos como o narrador de More nos apresenta este singular personagem:

Havia, entre os presentes, um parasita profissional que insistia em fazerse passar por louco, e representava esse papel tão bem que mal se podia distingui-lo de um verdadeiro doido. Suas tentativas de parecer engraçado eram tão canhestras que mais se ria dele do que das coisas que dizia. Às vezes, porém, acertava (MORE, 2009, p.49).

Já nesta apresentação, percebemos que o Bobo, por mais que se assemelhe ao louco, possui voz, e "às vezes acerta”. Ou seja, há espaço para ele, mesmo num colóquio sumamente importante, como é o caso. Isto ocorre porque o Bobo faz a "denúncia de toda espécie de convencionalismo pernicioso, falso, nas relações humanas" (BAKHTIN, 1998, p.278).

Estes personagens, seja qual for a extensão e relevância deles no enredo, são portadores da "revelação pública de esferas da vida especificamente privadas" (BAKHTIN, 1998, p.276). Pensando no Bobo da Utopia, percebemos exatamente esta ação. Ele evidencia como as elites clericais são pouco produtivas à sociedade, e isto é feito diante do próprio clero em resposta a certo frade:

Ah, mas não conseguireis livrar-vos dos mendigos tão facilmente, disse ele (o frade). O que seria de nós, frades mendicantes? Ora, mas isso já se acha perfeitamente resolvido, respondeu o parasita. Não foi o próprio cardeal quem acabou de estipular as mais sábias medidas para o controle e a proveitosa utilização de todos os vagabundos? (MORE, 2009, p.50).

Isto se dá pela característica ontológica do Bobo: "Tais personagens trazem consigo para a literatura, em primeiro lugar, uma ligação muito importante com os palcos teatrais e com os espetáculos de máscaras ao ar livre” (BAKHTIN, 1998, p.275).

Nota-se que há uma divergência entre o que é publicável e o que deve ser convencionalmente posto de lado. No entanto, para o Bobo, não há distinção entre o que deve ou não ser publicado, ele é autorizado para revelar, desvelar este convencionalismo:

Este convencionalismo pernicioso que impregnou a vida humana é, antes de tudo, a ordem e a ideologia feudais com a sua depreciação de tudo o que é espaço-temporal. A hipocrisia e a impostura impregnaram todas as relações humanas. As funções "naturais" oriundas da natureza humana realizam-se, por assim dizer, pelo contrabando selvagem, porque a 
ideologia não as consagra. Isto introduzia a falsidade e a duplicidade em toda a existência do homem. Todas as formas ideológico-institucionais tornavam-se hipócritas e falsas, enquanto que a vida real, privada de interpretação ideológica, tornava-se grosseiramente animal (BAKHTIN, 1998, p.278).

Refletindo sobre esta citação, constatamos que um fenômeno como Rabelais não poderia ter surgido em outra época, pois, ao expressar o homem hiperbolicamente grotesco, o francês purga a hipocrisia que, no humanismo renascentista, vivia sua máxima contradição, sua tensão maior. Esta tensão, este movimento de destronamentos, de relatividade do que era, até então, indiscutível, reflete-se em todas as formas sociais e/ou artísticas:

$\mathrm{Na}$ época da Renascença, as formas de romance que mencionamos destruíram aquela vertical do além, que tinha decomposto as formas do mundo espaço-temporal e o seu conteúdo qualitativo e vivo. Elas prepararam o restabelecimento da entidade material e espaço-temporal do mundo num estágio novo de desenvolvimento, mais aprofundado e complicado. Elas prepararam a assimilação pelo romance de um mundo onde, na mesma época descobria-se a América, o caminho marítimo para as Índias, um mundo que se abria às novas ciências naturais e à nova matemática (BAKHTIN, 1998, p.281).

A curta ação do Bobo na Utopia fica aparentemente sem grande função no todo da obra, mas é material suficiente para se compreender uma nota a mais da visão humanista do Renascimento. Neste contexto, o Bobo possuía seu lugar cativo nas composições literárias e folclóricas como um todo, pois era necessária e permitida a sua franqueza absoluta.

\section{Conclusões}

Buscamos, neste trabalho, aproveitar as reflexões do grande pensador russo Mikhail Bakhtin sobre o Renascimento e sua correspondente representação do homem para compreender melhor o célebre livro de Thomas More.

A Utopia, indubitavelmente, dialoga com toda a história passada, desde os mais recuados tempos até os contemporâneos de More; é um livro enciclopédico no mais alto grau. Por isso, até hoje, busca-se decifrar quem são os interlocutores, as teses refutadas, as teses corroboradas, as piscadelas para o leitor astuto, as críticas às ideologias presentes na realidade do escritor inglês, enfim, há um manancial riquíssimo ainda a ser ser deslindado.

Assim sendo, este trabalho não é mais do que se pretende que seja: meras observações pontuais (vindas de fontes confiáveis) sobre uma obra de repertório vastíssimo.

A Sátira menipeia, tão bem valorizada por Bakhtin, mostrou-se útil à compreensão da obra de More, pois em sua principal característica (a experimentação de determinada ideia) há similaridade entre ambas. Demos uma pequena mostra da funcionalidade de tal conceito, mas poderse-ia ampliar a reflexão sobre a Menipeia 
com vistas a outras obras pertencentes ao gênero utópico, e mesmo a certas obras da moderna ficção científica.

O destronamento, entendido na sua relação com a atmosfera carnavalesca, opera em diversas instâncias na obra de More. Contudo, interessou-nos a atitude destronante dos utopianos com relação ao capital, a tudo quanto poderia se tornar moeda, em detrimento dos valores humanos. Como se trata do período renascentista, o homem e seus valores mais rasos - porém reais e verdadeiramente humanos-, como vimos, dessublimam, destronam os valores pecuniários que obscurecem as relações entre os homens.

O personagem Bobo, que tão estranho nos soa e tão artificial nos parece, exerce, em todas as obras nas quais figura, uma função supinamente importante: por meio do exagero que faz rir, ele nos traz a verdade aos nossos olhos. Em Utopia, foi possível constatar que tudo quanto Bakhtin discorre sobre tal histriônico personagem é encontrado neste que aparece somente no Livro I do livro de Thomas More.

Ressaltamos que Bakhtin estuda o período em questão com vistas a sua compreensão do mundo e suas manifestações artísticas, busca dar voz à vertente não-oficial da cultura. Sem dúvida, More pertencia ao lado oficial da cultura europeia renascentista, e seu amigo Erasmo se aproximaria muito mais do que Bakhtin propõe em suas teorias aqui compendiadas. No entanto, o teor humanista de ambos é o mesmo, com expressões e representações do homem mais ou menos afinadas com o espírito popular, carnavalesco do Renascimento. Sendo assim, as questões relacionadas ao "riso", que o pensador russo como poucos teorizou, foram aplicáveis à trama utopiana.

\section{REFERÊNCIAS}

BAKHTIN, Mikhail. Questões de literatura e estética: a teoria do romance. $4^{\mathrm{a}}$ ed. Trad: Aurora F. Bernardini, José P. Júnior, Augusto G. Júnior, Helena S.Nazário, Homero F. de Andrade. São Paulo: Editora UNESP, 1998.

Problemas da Poética de Dostoiévski. Trad. Paulo Bezerra. Rio de Janeiro: Forense Universitária, 1997.

A Cultura Popular na Idade Média e no Renascimento: 0 contexto de François Rabelais. $4^{\mathrm{a}} \mathrm{ed}$. Trad: Iara Frateschi. São Paulo-Brasília: Edunb/ HUCITEC, 1999.

Estética da criação verbal. Trad. Paulo Bezerra. São Paulo: Martins Fontes, 2003.

BORGES, J.L. Ficciones. Madrid: Alianza Editorial, 2001.

El Aleph. Madrid: Alianza Editorial, 2004.

BUBER, Martin. Caminos de Utopía. Trad. J. Rovira Armengol. Ciudad de México: Breviarios, 1955.

CAMPANELLA, Tommaso. A Cidade do Sol in Os Pensadores. São Paulo: Abril Cultural, 1978.

MORE, Thomas. Utopia. Trad. Jefferson L. Camargo e Marcelo B. Cipolla. São Paulo: Martins Fontes, 2009.

NUNES, Benedito. 0 dorso do tigre. São Paulo: Editora Perspectiva, 1969.

Recebido para publicação em 14 de mar. de 2013 Aceito para publicação em 20 de out. de 2013 